Disponível em:

http://editora.unoesc.edu.br/index.php/race

Race, Joaçaba, v. 15, n. 1, p. 39-66, jan./abr. 2016

\title{
CUSTO DE CAPITAL, ENDIVIDAMENTO E SUSTENTABILIDADE EMPRESARIAL: UM ESTUDO NO MERCADO DE CAPITAIS BRASILEIRO NO PERÍODO DE 2009 A 2013
}

Fernanda Maciel Peixoto

E-mail: fmacielpeixoto@gmail.com

Doutora em Administração pela Universidade Federal de Minas Gerais; Mestre em Administração pela Universidade Federal de Uberlândia; Professora Adjunta da Faculdade de Gestão e Negócios, da Universidade Federal de Uberlândia.

Marielle Barcelos Pains

E-mail: mariellepains@hotmail.com Graduanda em Administração, na Faculdade de Gestão e Negócios, da Universidade Federal de Uberlândia.

Aracy Alves de Araújo

E-mail: aracy.araujo@gmail.com

Doutora em Economia Aplicada pela Universidade Federal de Viçosa; Mestre em Desenvolvimento e Meio Ambiente pela Universidade Federal do Piauí; Professora Adjunta da Faculdade de Gestão e Negócios, da Universidade Federal de Uberlândia.

Thayse Machado Guimarães

E-mail: thaysemg.adm@gmail.com Mestre em Administração pela Universidade Federal de Uberlândia; doutoranda em

Contabilidade Financeira pela Faculdade de Ciências Contábeis da Universidade Federal de Uberlândia; Professora da Faculdade de Gestão e Negócios, da Universidade Federal de Uberlândia. Endereço para correspondência: Avenida João Naves de Ávila, 2121, Santa Mônica, 38408-100, Uberlândia, Minas Gerais, Brasil.

Artigo recebido em 06 de novembro de 2014. Aceito em 24 de setembro de 2015. 
Resumo

O objetivo com este estudo foi verificar quais os efeitos da decisão de uma empresa em aderir ao Índice de Sustentabilidade Empresarial (ISE) sobre seu custo de capital e endividamento, no período de 2009 a 2013. Sabe-se que as discussões em torno da sustentabilidade nas duas últimas décadas no Brasil mostram a crescente adoção de uma consciência ecológica e socialmente responsável em diferentes setores da sociedade, em especial no meio empresarial. As empresas que aderem a índices de sustentabilidade buscam melhorar a imagem, reduzir a percepção de risco e aumentar sua credibilidade no mercado em que atuam. O quadro teórico de referência se baseou, principalmente, nos estudos de Peixoto (2012) e de Teixeira, Nossa e Funchal (2011). Quanto aos procedimentos metodológicos adotados, utilizaram-se os métodos de regressão Pooled OLS e Painel, com efeitos fixos e aleatórios. Os resultados revelaram que existe uma relação negativa entre a adesão ao ISE e custo de capital, bem como entre a adesão ao ISE e o endividamento, confirmando as hipóteses iniciais e a literatura sobre o tema. Ademais, notou-se que as empresas pertencentes aos setores de energia elétrica, fundos e software e dados tendem a ter uma elevação no risco da estrutura interna de capital, enquanto as dos setores de construção, de minerais não metálicos e de mineração tendem a ter seu risco reduzido. Observou-se, ainda, que as empresas do setor de eletrônicos tendem a apresentar uma estrutura de capital menos alavancada.

Palavras-chave: Sustentabilidade. ISE. Custo de capital. Endividamento.

\title{
Cost of capital, indebtedness and corporate sustainability: a study in the brazilian capital market from 2009 to 2013
}

\begin{abstract}
The aim with this paper was to determine what are the effects of the decision of a company to join the Corporate Sustainability Index (ISE) on in its cost of capital and indebtedness, in the period 2009 to 2013. It is known that the discussions involving sustainability in the last two decades in Brazil shows the increasing adoption of environmental awareness and social responsibility in different sectors of society, especially in the business world. Companies that adhere to sustainability indices seek to improve the image, reduce risk perception and increase their credibility in the market in which they operate. The theoretical framework was based mainly on studies of Peixoto (2012) and Teixeira, Nossa and Funchal (2011). In relation to the adopted methodological procedures, we used Pooled-OLS and Painel regression methods with fixed and random effects. The results revealed that there is a negative relationship between adherence to the ISE and cost of capital, and between adherence to the ISE and indebtedness, confirming the initial hypothesis and the literature on the subject. Furthermore, it was noted that companies belonging to electrical energy, funds and software and data tend to have a high risk of internal capital structure, while the construction sector, non-metallic minerals and the
\end{abstract}


mining companies tend to have their risk reduced. It also was noted that the electronics sector companies tend to have a less leveraged capital structure.

Keywords: Sustainability. CSI. Cost of capital. Indebtedness.

\section{INTRODUÇÃO}

O tema sustentabilidade empresarial no Brasil ganhou força especialmente a partir da década de 1990, sendo motivo de recorrente debate na mídia, na academia e em meio às políticas empresariais (ARBACHE, 2013). A Conferência Rio+20, realizada em junho de 2012, teve o Brasil como palco das discussões sobre o assunto, destacando a necessidade de agir em prol de diretrizes sustentáveis, que atendam às demandas do crescimento econômico, com o objetivo de alcançar um desenvolvimento mais sustentável (ARBACHE, 2012).

O mercado, que está cada dia mais aberto e competitivo, sob influência das questões supracitadas, naturalmente faz com que as empresas tenham que se preocupar com o controle dos impactos ambientais. A princípio, esse cenário parece direcionar as organizações para uma análise mais aprofundada de suas relações com a natureza. Todavia, recomenda-se que seja encarado como uma oportunidade para que elas implementem práticas sustentáveis de gerenciamento, não apenas como uma postura reativa a exigências legais ou pressões de grupos ambientalistas, mas, sim, com a intenção de obter vantagens competitivas (KRAEMER, 2005).

A sustentabilidade corporativa pode trazer alguns benefícios de longo prazo, os quais exigem gastos no presente. Contudo, há empresas que têm observado a contrapartida de seus gastos e orientado suas expectativas de acordo com o que certos pesquisadores abordam, como Anderson (2006), que declara que o tratamento de riscos relacionados ao meio ambiente traz vantagens, que têm a ver com a criação de valor para os acionistas, redução do custo de capital e do endividamento, demandas por investidores e clientes, bem como melhora da reputação e criação de vantagem competitiva.

Há alguns anos iniciou-se a tendência de os investidores buscarem por empresas que adotem práticas de sustentabilidade e responsabilidade social para aplicar seus recursos, com o propósito de escolher aquelas que apresentam uma melhor imagem perante a sociedade. Isso ocorre pois consideram que tais empresas possuem melhor capacidade de gerar maior valor para o acionista em longo prazo (BISCO, 2009).

Essa tendência de valorizar empresas que incorporaram os princípios da Sustentabilidade na sua gestão também engloba a consideração de que por conhecerem mais os riscos e oportunidades do negócio, estas têm maior chance de realizar uma gestão financeira mais eficiente, fazendo que sejam vistas pelos investidores como uma 
fonte mais segura para os seus investimentos de longo prazo. Tal segurança tornou-se ainda mais importante após a crise econômica mundial de 2008, pois nesse período ficou evidente a necessidade de os investidores repensarem seus critérios de investimento, focando a gestão financeira do negócio (MARCONDES; BACARJI, 2010).

Observando-se os possíveis impactos gerados pela sustentabilidade empresarial, com este trabalho pretendeu-se verificar quais os efeitos da decisão de uma empresa em aderir ao Índice de Sustentabilidade Empresarial (ISE) sobre seu custo de capital e endividamento. De forma mais específica, houve o intuito de avaliar se a adesão ao ISE afeta o custo de capital e o nível da dívida de 200 empresas brasileiras de capital aberto não financeiras no período de 2009 a 2013.

Esta pesquisa apresenta contribuições teóricas e práticas, por envolver um tema que tem sido especialmente analisado nas duas últimas décadas. A contribuição teórico-empírica compreendeu o entendimento da relação estabelecida entre a adesão ao ISE e o custo de capital e endividamento das organizações. Espera-se que as empresas que possuem uma consciência ecológica, bem como uma postura socialmente responsável, possam melhorar sua imagem, reduzir a percepção do risco e aumentar a credibilidade no mercado. Observou-se uma carência de estudos que tratem da Sustentabilidade Empresarial com aspectos financeiros do custo de capital e do endividamento, o que justifica a relevância deste trabalho para a área de Finanças. A contribuição prática, por sua vez, envolveu investigar se as empresas mais sustentáveis de fato garantem maior valor aos acionistas em longo prazo.

\section{REFERENCIAL TEÓRICO}

\subsection{IMPORTÂNCIA DA SUSTENTABILIDADE EMPRESARIAL}

A Sustentabilidade Empresarial (SE) vem sendo considerada um investimento ou negócio estratégico que visa adotar melhores práticas de gestão que vão ao encontro das necessidades atuais e futuras dos stakeholders (ANDRADE; MOREIRA; PEDROSA, 2012). Esse conceito, como sugerido por Artiach et al. (2010), corresponde à difícil tarefa de fornecer resultados competitivos em curto prazo e, simultaneamente, procurar proteger, sustentar e resguardar os recursos naturais e humanos necessários no futuro.

Um importante conceito associado à sustentabilidade empresarial é o Triple Bottom Line, que significa que a SE faz referência à prosperidade econômica, à qualidade ambiental e à justiça social, integrando, assim, o desempenho financeiro, ambiental e social. Em suma, pode-se dizer que o termo SE, além de incluir critérios 
econômicos, faz a junção de aspectos socioambientais no processo decisório e na estratégia corporativa, a fim de criar vantagens competitivas sustentáveis de longo prazo (ELKINGTON, 1998; WAJNBERG; LEMME, 2009).

Ao tratar da dimensão econômica, Harris et al. (2001) explicam que um sistema economicamente sustentável precisa ter a capacidade de produzir produtos e serviços de forma contínua sem provocar problemas nos aspectos fiscais e financeiros. Na questão social, um sistema passa a ser sustentável ao proporcionar justiça na distribuição de renda e oportunidades, igualdade de tratamento, e com serviços sociais, como em saúde e educação. Quanto à terceira dimensão, a ambiental, parte-se do preceito de que a sustentabilidade ocorre quando não se comprometem as bases de recursos, renováveis ou não renováveis, por utilizá-las com parcimônia, baseando-se no propósito de manter a biodiversidade, a estabilidade da atmosfera e outras funções do ecossistema.

Voltando o foco para a questão econômica, os autores Claro, Claro e Amancio (2008) sugerem a existência de benefícios que podem ser derivados da economia de custos ou incremento de receitas. Há, ainda, benefícios estratégicos resultantes da melhoria da imagem institucional, da melhoria nas relações de trabalho e nas relações com os órgãos governamentais, comunidade e grupos ambientalistas. Essa ideia de melhoria da imagem é congruente com o pensamento de Dias, Zavaglia e Cassar (2003), que acreditam que empresas seguidoras de princípios de sustentabilidade são vistas de forma diferente pelo público consumidor, que tem aumentado sua consciência ambiental, o que gera maior aceitação de sua imagem no mercado.

Em suma, duas razões principais podem ser apontadas para a preocupação gerencial com questões ambientais: a pressão dos stakeholders, que tem aumentado com a preocupação a respeito do impacto que as atividades da empresa podem ter no meio ambiente, e os custos relevantes e substanciais dos impactos ambientais, que fazem com que a informação ambiental seja economicamente influenciadora no processo decisório e para o accountability, ou obrigação de prestar contas (SCHALTEGGER; BURRITT, 2000).

Com base nos eventos e discussões em torno da sustentabilidade nas duas últimas décadas no Brasil, aos poucos se iniciou a tendência de os investidores desejarem aplicar seus recursos em empresas caracterizadas como socialmente responsáveis, sustentáveis e rentáveis, dado em que se considera que uma empresa sustentável pode, em longo prazo, gerar um valor maior ao estar mais preparada para enfrentar riscos econômicos e socioambientais (BM\&FBOVESPA, 2014a).

Com o objetivo de acompanhar tal tendência, a BM\&FBovespa, com várias instituições - ABRAPP, ANBIMA, APIMEC, IBGC, IFC, Instituto ETHOS e Minis- 
tério do Meio Ambiente -, criou em 2005 um índice de ações que pudesse ser um referencial para os investimentos socialmente responsáveis, denominado Índice de Sustentabilidade Empresarial (ISE). Destaca-se que o ISE foi originalmente financiado pela International Finance Corporation (IFC), braço financeiro do Banco Mundial, e o responsável pela elaboração da metodologia do Índice foi o Centro de Estudos em Sustentabilidade (GVCes), da Escola de Administração de Empresas de São Paulo da Fundação Getúlio Vargas (FGV-EAESP). O cálculo e a gestão técnica do índice são de responsabilidade da Bolsa (BM\&FBOVESPA, 2014a).

O ISE foi criado com o mesmo intuito dos índices internacionais Dow Jones Sustainability (DJSI), FTSE4 Good Series e Johannesburg Stock Exchange SRI Index. Sendo uma iniciativa pioneira na América Latina, a BM\&FBovespa (2014a) postula que o ISE procura criar um ambiente de investimento que seja compatível com as demandas de desenvolvimento sustentável da sociedade contemporânea e estimular mais investimentos em responsabilidade social e corporativa. Trata-se, em síntese, de uma ferramenta para analisar comparativamente a performance das empresas listadas na BM\&FBovespa em vista do fator sustentabilidade corporativa, pautada em eficiência econômica, equilíbrio ambiental, justiça social e governança corporativa.

Para fazer parte desse índice, os ativos das companhias devem atender cumulativamente aos seguintes critérios: estar entre os ativos elegíveis que, no período de vigência dos 12 meses anteriores, em ordem decrescente de Índice de Negociabilidade (IN), ocupem as 200 primeiras posições; ter sido negociado em pelo menos 50\% dos pregões dos doze meses anteriores; não ser classificado como Penny Stock (ações abaixo de um real); atender aos critérios de sustentabilidade e ser selecionado pelo Conselho Deliberativo do ISE. Caso o ativo de uma empresa atenda a todos esses critérios, todas as espécies de sua emissão participarão da carteira do índice, desde que estejam entre os ativos elegíveis que, no período de vigência das três carteiras anteriores (um ano), em ordem decrescente de Índice de Negociabilidade (IN), representem, em conjunto, 99\% (noventa e nove por cento) do somatório total desses indicadores (BM\&FBOVESPA, 2014b).

Ainda que recebam incentivos dos órgãos reguladores do mercado, como a BM\&FBovespa, os estudos sobre o tema ainda não conseguiram consolidar uma corrente teórica que melhor evidencie a relação entre investimentos socialmente responsáveis e desempenho das empresas e criação de valor aos acionistas (ANDRADE; MOREIRA; PEDROSA, 2012). Ademais, observa-se, principalmente no Brasil, uma carência de estudos que tratem da SE com os aspectos financeiros do custo de capital e do endividamento, lacuna essa que este trabalho pretende explorar. 


\subsection{CUSTO DE CAPITAL, ENDIVIDAMENTO E SUSTENTABILIDADE EMPRESARIAL}

Neste trabalho, ao se propor identificar a relação entre sustentabilidade empresarial e custo de capital/endividamento em empresas de capital aberto brasileiras, demandam-se algumas explicações sobre custo de capital, que representa o risco da estrutura interna de capital da empresa, e sobre endividamento.

Em seus estudos, Skaife, Collins e LaFond (2004) e Lameira (2007) utilizam a variável WACC (Weighted Average Costof Capital ou Custo Médio Ponderado de Capital) para representar o custo implícito de capital das firmas ou o chamado risco da estrutura interna de capital da empresa. Dessa forma, os autores argumentam que enquanto o beta representa o risco sistemático de mercado (perspectiva externa), o WACC representa o risco interno (próprio) da estrutura de capital de cada empresa.

De acordo com Assaf Neto (2009), o WACC pode ser definido como o retorno mínimo exigido por credores e acionistas, sendo determinado pela ponderação de cada fonte de financiamento da firma com seu respectivo custo. Essa taxa representa, na essência, a remuneração média exigida por credores e acionistas em suas aplicações de capital, de maneira a remunerar o risco assumido no negócio.

Quanto ao aspecto endividamento, Assaf Neto (2006) define que os indicadores de endividamento são utilizados para aferir a composição das fontes passivas de recursos de uma empresa. Dessa forma, eles indicam como os recursos de terceiros são utilizados pela empresa e qual a sua participação no passivo total. A alavancagem, ou nível de endividamento da firma, não deixa de ser uma forma de mensurar o risco interno da empresa, já que, no geral, empresas mais endividadas são consideradas mais arriscadas pelos investidores no mercado.

Dada a importância do tema, alguns estudos tratam de possíveis relações entre sustentabilidade e risco/custo de capital/endividamento, entre as quais citam-se a seguir, as mais relevantes.

Uma importante perspectiva é apontada por Vellani, Albuquerque e Chaves (2009), que consideram que ao manter ações sociais e ecológicas, uma empresa pode obter desempenho social e ambiental, que, em adição ao desempenho econômico, é capaz de direcioná-la à sustentabilidade, podendo reduzir o risco do negócio.

Em linha similar, Lameira et al. (2013) realizaram um estudo com o intuito de investigar se as empresas que estão incluídas no ISE são as que têm melhor desempenho, menor risco e maior valor de mercado. Como metodologia, foi feita uma pesquisa exploratória com caráter quantitativo. Construiu-se um banco de dados de 
informações econômicas e financeiras de 205 empresas listadas na bolsa de valores de São Paulo, no período de 2005 a 2009. Aplicaram-se os métodos de regressão linear com mínimos quadrados ordinários em um e dois estágios e o método de momentos generalizados, a fim de analisar a possível associação entre participar do ISE da BM\&FBovespa e apresentar melhores indicadores de desempenho, risco e valor. De forma geral, os resultados do estudo indicaram haver uma associação positiva entre a inclusão no ISE e melhores indicadores de desempenho e valor das empresas. E os resultados da associação entre ISE e os indicadores de risco (em especial a volatilidade) apresentaram uma associação negativa, conforme esperado (LAMEIRA et al., 2013).

Por sua vez, Nogueira e Gomes (2012) desenvolveram um trabalho cuja proposta foi analisar o desempenho do ISE quanto ao seu retorno e risco, comparativamente com outros índices da BM\&FBovespa. Para isso, implementaram uma pesquisa exploratória com dados secundários, em que os índices foram analisados e o Índice de Sharpe foi utilizado como ferramenta para avaliação da eficiência dos índices de ações. Primeiramente, os autores observaram semelhança nos resultados, e que o ISE superou os resultados de alguns dos demais índices da BM\&FBovespa. Ademais, o ISE apresentou resultados positivos para o Índice de Sharpe, indicando que o risco que ele oferece é recompensado, superando resultados de alguns outros índices da bolsa, como ITEL, IMOB, ITAG, IVBX e IFNC, o que faz com que ele se mostre como um investimento atrativo.

Cavalcanti e Boente (2012) também investigaram a relação entre risco e retorno das empresas integrantes do ISE no período de 2008 a 2010, a fim de verificar se elas apresentaram retornos médios maiores e riscos sistêmicos menores. Os sites da BM\&FBovespa e GVCES serviram como fonte de coleta de dados sobre a pontuação diária do ISE, as cotações diárias das ações das empresas da amostra e do grupo de controle e a lista de empresas integrantes do ISE no período investigado. Além disso, foram utilizadas duas ferramentas estatísticas: o modelo CAPM, para medição do risco sistemático a partir da fórmula do beta, e o teste $\mathrm{F}$ a 5\% de significância, para calcular diferenças entre as médias de retornos e riscos sistêmicos dos grupos em análise. Com base na metodologia aplicada, os resultados não apontaram diferenças significativas entre os valores dos retornos médios e dos riscos sistemáticos das empresas da amostra em comparação às do grupo de controle. Segundo os autores, isso sugere que o mercado acionário brasileiro ainda não identificou vantagens significativas em valorizar ações de empresas sustentáveis (CAVALCANTI; BOENTE, 2012).

Para o presente estudo, foi relevante o trabalho realizado por Teixeira, Nossa e Funchal (2011). Os autores investigaram a relação entre ISE e risco para uma amostra de 378 empresas no período de 2003 a 2008. De forma complementar, avaliaram se a forma 
de financiamento das empresas é afetada pela participação das firmas no ISE. Foi adotado o método conhecido como natural ou quase experimental - com dados em painel e duplo efeito fixo - projetado por meio de séries cronológicas, em que são realizados testes estatísticos entre grupos de tratamento e grupos de controle ou comparação. Esses grupos representam a amostra em que o grupo de tratamento é composto pelas empresas que foram qualificadas anualmente no ISE, e o grupo de controle, pelas outras empresas que pertenceram à amostra e também estão listadas na BM\&FBovespa, mas não pertencem ao ISE.

Mesmo com o ISE tendo sido criado apenas em dezembro de 2005, o estudo supracitado compreende os anos 2003 a 2008, a fim de comparar os dois grupos três anos antes da primeira carteira (2003-2005) e três anos após a criação da carteira (2006-2008). Para as empresas que adotam práticas de cunho socioambiental, os resultados mostraram haver uma relação negativa do ISE com o endividamento e com o risco. Assim, foram constatados indícios de que empresas participantes do ISE no período estudado tiveram o indicador de risco/endividamento reduzido quando comparadas às que não participam do Índice (TEIXEIRA; NOSSA; FUNCHAL, 2011).

Sob a mesma ótica, o estudo de Vital et al. (2009) teve como objetivo verificar a existência de tendência nos indicadores financeiros das empresas - entre estes, de endividamento - que realizam práticas de sustentabilidade, ou não. A amostra analisada foi composta por 20 empresas de capital aberto da BM\&FBovespa, das quais, para fins de comparação, metade pertencia ao ISE e metade não. Foi utilizada a análise de média dos indicadores das empresas do ISE e das que não participavam do ISE. Como resultados, encontrou-se um maior endividamento para as empresas participantes do ISE, o que, segundo os autores, prejudicou aspectos como a rentabilidade e a lucratividade delas. Percebeu-se que empresas não participantes do ISE privilegiam os recursos próprios na composição de seus investimentos, o que, por sua vez, pode proporcionar a elas um menor risco.

Pode-se destacar, ainda, que o ISE da BM\&FBovespa possui como uma de suas dimensões a Governança Corporativa. Isto é, o questionário que as empresas devem preencher para obtenção de seu nível de sustentabilidade considera diversos aspectos da governança, como proteção aos acionistas minoritários, transparência, conselhos de administração e estrutura de propriedade e controle. Dada essa informação, utilizou-se neste estudo o trabalho de Peixoto (2012) sobre governança e risco, para auxiliar na elaboração dos modelos econométricos desta pesquisa. A hipótese subjacente é a de que empresas bem governadas e mais sustentáveis (por comporem o ISE) apresentarão, em decorrência, um menor risco. A adaptação do modelo de Peixoto (2012) será possível, pois, mesmo tratando de temas diferentes, o fato de o questionário que compõe o ISE possuir a dimensão de governança corporativa permi- 
te que seja usado um modelo econométrico similar para ambas as abordagens, o que será delineado posteriormente na metodologia.

Peixoto (2012) analisou a relação entre os mecanismos de governança corporativa e o risco, além do desempenho contábil e valor de empresas brasileiras de capital aberto não financeiras listadas na BM\&FBovespa, tanto em períodos de crise quanto de não crise. A amostra compreendeu 245 empresas brasileiras de capital aberto listadas na BM\&FBovespa, no período de 2000 a 2009. Foram utilizadas técnicas estatísticas para produzir um índice consolidado que representasse todas as variáveis de qualidade da governança. A partir dos estudos existentes, o autor pressupôs que haveria uma relação negativa entre governança e risco. Como resultados, observou-se que não houve associação significativa entre WACC e qualquer dos índices de qualidade da governança, bem como os modelos cuja variável dependente era o beta também não mostraram relações significativas com a GC. Isso contrariou a hipótese citada anteriormente, além da literatura sobre o tema pesquisado por Peixoto (2012). A ressalva é que empresas que pertencem ao Nível 1 de GC da bolsa apresentaram menor WACC no período de crise.

Nota-se, pelo exposto, que as pesquisas sobre a relação entre adesão ao ISE e o risco/endividamento das empresas no Brasil demonstram resultados conflitantes ou não muito evidentes - com diferentes abordagens metodológicas. Ruf et al. (2001) apontam algumas razões teóricas e metodológicas para essas controvérsias, entre elas, a falta tanto de fundamentação teórica e medidas sistemáticas e apropriadas do desempenho socioambiental, quanto, ainda, de rigor metodológico. Além disso, fala-se do tamanho reduzido e outras limitações de composição das amostras, bem como a possível incompatibilidade entre variáveis socioambientais e financeiras.

\section{METODOLOGIA}

\subsection{DADOS, AMOSTRA, MÉTODO E MODELOS ESTIMADOS}

O presente estudo pode ser caracterizado como descritivo e quantitativo. A amostra final foi composta por 200 empresas brasileiras de capital aberto não financeiras, listadas na BM\&FBovespa, envolvendo empresas listadas, ou não, no Índice de Sustentabilidade Empresarial (ISE), no período de 2009 a 2013. Restringiu-se a seleção às instituições não financeiras pelo fato de as instituições financeiras possuírem contas diferenciadas em seus demonstrativos e características que são bem específicas ao seu setor de atividade.

Para formar a amostra do estudo, consideraram-se como empresas com liquidez significativa aquelas que apresentaram índice de liquidez anual calculado pelo Economática superior a 0,001\% do índice correspondente à empresa com ações mais 
líquidas em quatro anos ou mais da pesquisa, incluindo, necessariamente, o ano 2013, conforme o critério adotado por Silveira (2004).

Formou-se, então, um painel desbalanceado de 1.059 observações-ano, quantidade suficiente para se realizarem as análises de regressão com dados em painel. Desse total de observações-ano, 87,35\% são referentes a firmas que não fazem parte do ISE, e 12,65\% correspondem a firmas que fazem parte do ISE da BM\&FBovespa.

Os dados coletados foram secundários, obtidos na base Economática e no site da BM\&FBovespa, sendo a primeira fonte usada para coleta dos dados financeiros e a segunda fonte adotada para verificar quais empresas estavam ou não listadas no ISE.

Feita a tabulação dos dados, foi possível dar sequência à análise quantitativa dos dados. Tal análise envolveu dois métodos estatísticos: (1) regressão múltipla por Mínimos Quadrados Ordinários - MQO (também chamada de Pooled - OLS ou POLS); e (2) regressão múltipla com dados em painel. Procederam-se aos testes Lagrange Multiplier e Breusch Pagan para verificar a presença de heterogeneidade nas unidades cross-section. No caso de opção pelo método Painel, foi necessário testar os modelos envolvidos na regressão, utilizando os modelos de efeitos fixos ou aleatórios, por meio do Teste de Hausman. Nos modelos onde havia problemas de heterocedasticidade e autocorrelação, utilizou-se a correção robust do software Stata 11.

Em suma, os três principais modelos econométricos estimados foram baseados em adaptações dos estudos de Peixoto (2012) e de Teixeira, Nossa e Funchal (2011), sendo todos controlados por setor e ano. Do estudo de Peixoto (2012), foi adaptado o seguinte modelo econométrico para o custo de capital:

WACC $_{\text {it }}=\beta_{0}+\beta_{1}$ ISE $_{\text {it }}+\beta_{2}$ beta $_{\text {it }}+\beta_{3}$ Book-to-Market $_{\text {it }}+\beta_{4}$ logvm $_{\text {it }}+\beta_{5}$ liquidez $_{\text {it }}+\beta_{6}$ dy $_{\text {it }}+\varepsilon_{\text {it }}$

Já os modelos econométricos adaptados de Teixeira, Nossa e Funchal (2011), para os aspectos custo de capital e endividamento, foram:

$$
\begin{aligned}
& \text { WACC }_{i t}=\beta_{0}+\beta_{1} \text { ISE }_{\text {it }}+\beta_{2} \operatorname{LnRecLíq}_{i t}+\beta_{3} \text { LiqGeral }_{\text {it }}+\beta_{4} \text { ROA }_{i t}+\beta_{5} \text { Tangib }_{i t}+\varepsilon_{i t} \\
& \mathrm{DE}_{\mathrm{it}}=\beta_{0}+\beta_{1} \mathrm{ISE}_{\mathrm{it}}+\beta_{2} \operatorname{LnRecLíq}_{\mathrm{it}}+\beta_{3} \mathrm{LiqGeral}_{\mathrm{it}}+\beta_{4} \mathrm{ROA}_{\mathrm{it}}+\beta_{5} \text { Tangib }_{\mathrm{it}}+\varepsilon_{\mathrm{it}}
\end{aligned}
$$

Em que:

$\mathrm{i}=$ indicador cross section

$\mathrm{t}=$ indicador de tempo

$\beta=$ coeficientes associados às variáveis independentes e de controle 
$\varepsilon=$ termo de erro das equações

As demais variáveis são descritas no Quadro 1.

Ressalta-se que os modelos estimados foram controlados por setor do Economática e por dummies de ano, para verificar os efeitos setoriais e temporais sobre as variáveis explicativas. Na próxima seção, são explicadas e justificadas as variáveis selecionadas para os modelos econométricos.

\subsection{VARIÁVEIS SELECIONADAS PARA O ESTUDO}

Diversas variáveis foram coletadas com o objetivo de testar as relações existentes entre custo de capital/endividamento e sustentabilidade empresarial, sendo esta medida por meio do índice de Sustentabilidade Empresarial da bolsa. No Quadro 1 encontram-se maiores detalhes sobre essas variáveis, como suas descrições, fórmulas, autores que fizeram uso das mesmas variáveis e resultados esperados em relação ao ISE e ao custo de capital/endividamento.

Quadro 1 - Variáveis usadas na pesquisa, sinais esperados, justificativas e fundamentação teórica.

\begin{tabular}{|c|c|c|}
\hline \multicolumn{3}{|c|}{ Variável de sustentabilidade empresarial (variável teste) } \\
\hline 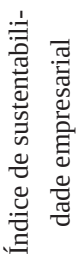 & ISE & $\begin{array}{l}\text { Variável dummy que assume valor } 1 \text { caso a empresa seja integrante da carteira do } \\
\text { ISE da BM\&FBovespa e valor } 0 \text { caso contrário. Supõe-se que boas práticas de } \\
\text { sustentabilidade se encontram associadas a melhor desempenho, maior valor e me- } \\
\text { nor risco (CLARO; CLARO; ARAKI, 2013; LAMEIRA et al., 2013; TEIXEIRA; } \\
\text { NOSSA; FUNCHAL, 2011; ANDRADE et al., 2013). }\end{array}$ \\
\hline \multicolumn{3}{|r|}{ Variáveis para custo de capital e endividamento (variáveis dependentes) } \\
\hline 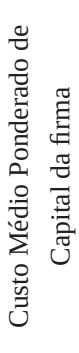 & $\begin{array}{l}\text { CMPC } \\
\text { ou } \\
W A C C^{1}\end{array}$ & $\begin{array}{l}\text { Representa o risco da estrutura interna de capital da empresa. O WACC é calculado } \\
\text { da seguinte forma: } \\
W A C C=\left\{\frac{\left.E B I T^{*}(I-I)+D-I\right]}{(E Q U I T Y+D E B T)} *[I+(I-P a y o u t) * R O A]\right\}+[(1-P \text { ayout }) * R O A] \\
\text { Acredita-se que as companhias com melhores práticas de sustentabilidade possuem } \\
\text { menores riscos na percepção interna. Assim, espera-se uma relação negativa entre } \\
\text { a participação no índice de sustentabilidade da BM\&FBovespa e os indicadores de } \\
\text { risco das empresas, (-) (LAMEIRA et al., 2013; PEIXOTO, 2012). }\end{array}$ \\
\hline
\end{tabular}




\begin{tabular}{|c|c|c|}
\hline 窇 & $\mathrm{DE}$ & $\begin{array}{l}\text { Relação entre endividamento e capital - Debt e Equity. A fórmula do } D E \text { é: } \\
\text { DE }=\frac{\text { Dívida Bruta }}{\text { Patrimônio líquido da empresa }} \\
\text { Espera-se que empresas participantes do ISE no período estudado apresentem } \\
\text { endividamento reduzido quando comparadas às que não participam do índice (TEI- } \\
\text { XEIRA; NOSSA; FUNCHAL, 2011). }\end{array}$ \\
\hline \multicolumn{3}{|r|}{ Variáveis de controle } \\
\hline 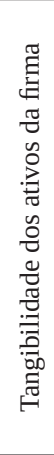 & Tangib & $\begin{array}{l}\text { Consiste na somatória do estoque e o imobilizado. } \\
\text { Tangibilidade = Estoque + Imobilizado } \\
\text { Ajuda a mensurar a estrutura/composição dos ativos. Empresas que possuem maior } \\
\text { proporção de ativos tangíveis podem fazer deles garantias, diminuindo o custo do } \\
\text { endividamento. Esses ativos são mais facilmente avaliados pelo mercado e mais } \\
\text { propensos à relação de troca. Assim, empresas com mais ativos tangíveis podem } \\
\text { estar mais propensas ao endividamento, aspecto esse relacionado ao risco de uma } \\
\text { empresa (TEIXEIRA; NOSSA; FUNCHAL, 2011). }\end{array}$ \\
\hline 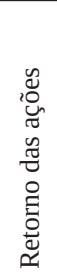 & $\begin{array}{l}\text { Book-to- } \\
\text {-Market }\end{array}$ & $\begin{array}{l}\text { Logaritmo natural do valor patrimonial da ação dividido por seu preço - logvpap. } \\
\text { Em relação ao WACC, espera-se relação negativa (PEIXOTO, 2012). Sua fórmula } \\
\text { é: } \\
\text { Book - to - Market }=\frac{\text { valor patrimonial da ação }}{\text { preço }}\end{array}$ \\
\hline 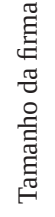 & Lnrol & $\begin{array}{l}\text { Logaritmo natural da receita operacional líquida como proxy de tamanho da em- } \\
\text { presa. Empresas de tamanhos maiores normalmente estão associadas a menores } \\
\text { riscos (menores betas e menores custos de capital) (TEIXEIRA; NOSSA; FUN- } \\
\text { CHAL, 2011; ANDRADE et al., 2013; OLIVEIRA, 2013; LAMEIRA, 2012). }\end{array}$ \\
\hline 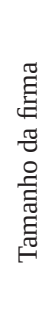 & Logvm & $\begin{array}{l}\text { Logaritmo natural do valor de mercado (proxy para tamanho da firma) (PEIXOTO, } \\
\text { 2012). Essa variável é calculada pela fórmula: } \\
\text { logvm = preço de fechamento da ação } \times \text { quantidade de ações } \\
\text { Espera-se que o tamanho da firma medido pelo logvm mostre relação positiva com } \\
\text { o WACC (PEIXOTO, 2012). }\end{array}$ \\
\hline
\end{tabular}




\begin{tabular}{|c|c|c|}
\hline 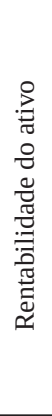 & ROA & $\begin{array}{l}\text { A rentabilidade do ativo (ROA) mede o potencial de geração de lucro da empresa } \\
\text { (MATARAZZO, 2007). Sua fórmula é: } \\
\text { ROA }=\frac{\text { Lucro Líquido }(L L)}{\text { Ativo Total }(A T)} \\
\text { Diferentes estudos fizeram uso dessa variável (TEIXEIRA; NOSSA; FUNCHAL, } \\
\text { 2011; ANDRADE et al., 2013). Oliveira (2013) encontrou que o desempenho ope- } \\
\text { racional medido pelo ROA melhora quando a empresa adota práticas sustentáveis. }\end{array}$ \\
\hline & Dy & $\begin{array}{l}\text { Variável indicativa do rendimento em dividendos. Obtida por meio da divisão entre } \\
\text { o dividendo pago por ação no ano anterior e o preço da ação no final do exercício } \\
\text { social (PEIXOTO, 2012). Assim, sua fórmula é: } \\
d y=\frac{\text { dividendo por ação }}{\text { preço da ação }} \\
\text { De acordo com Peixoto (2012), espera-se que exista relação negativa entre a variá- } \\
\text { vel dividendyeld e o custo médio ponderado de capital (WACC). }\end{array}$ \\
\hline 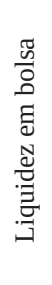 & Liquidez & $\begin{array}{l}\text { Valor da liquidez das ações da empresa em bolsa (LAMEIRA, 2012; LAMEIRA et } \\
\text { al., 2013). A fórmula de liquidez em bolsa é: } \\
\text { liqbol }=100 *\left(\frac{p}{P}\right) * \sqrt{\left(\frac{n}{N}\right) *\left(\frac{V}{V}\right)} \\
\text { No estudo de Peixoto (2012), a variável liquidez em bolsa impacta positivamente } \\
\text { o WACC. }\end{array}$ \\
\hline 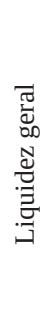 & LiqGeral & $\begin{array}{l}\text { Liquidez geral da firma é calculada a partir da seguinte fórmula: } \\
\text { LiqGeral }=\frac{\text { Ativo Circulante }+ \text { Realizável a Longo Prazo }}{\text { Passivo Circulante }+ \text { Exigível a Longo Prazo }} \\
\text { É esperado que a liquidez geral possua uma relação negativa com o endividamento } \\
\text { (TEIXEIRA; NOSSA; FUNCHAL, 2011). }\end{array}$ \\
\hline 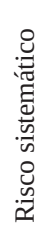 & Beta & $\begin{array}{l}\text { Representa o risco sistemático da empresa “i” no período “t”, e foi obtido pela } \\
\text { regressão do retorno mensal do título contra o retorno mensal do índice de mer- } \\
\text { cado (Ibovespa). Para a obtenção do beta, foram usadas informações de } 60 \text { meses } \\
\text { anteriores. (LAMEIRA et al., 2013; PEIXOTO, 2012; TEIXEIRA; NOSSA; FUN- } \\
\text { CHAL, 2011). Acredita-se, a priori, que exista uma relação positiva entre beta e } \\
\text { WACC (+) (PEIXOTO, 2012). }\end{array}$ \\
\hline
\end{tabular}




\begin{tabular}{|l|l|l|}
\hline & & $\begin{array}{l}\text { Dummies de tempo/ano (CLARO; CLARO; ARAKI, 2013; TEIXEIRA; NOSSA; } \\
\text { FUNCHAL, 2011; OLIVEIRA, 2013). O efeito fixo no tempo pode ser implemen- } \\
\text { tado ao se usar um conjunto de dummies de tempo, uma para cada ano, capturando, } \\
\text { por exemplo, choques na economia que afetam todas as firmas. }\end{array}$ \\
\hline 苞 & Setor & $\begin{array}{l}\text { Variáveis dummies para representar os setores da Economática e verificar se o } \\
\text { custo de capital/endividamento da firma se comporta de forma distinta entre os } \\
\text { setores de atividades (TEIXEIRA; NOSSA; FUNCHAL, 2011; OLIVEIRA, 2013; } \\
\text { PEIXOTO, 2012). }\end{array}$ \\
\hline
\end{tabular}

Fonte: os autores.

Após o delineamento das variáveis selecionadas para este estudo, seus sinais esperados, justificativas e literatura em que se baseiam, passa-se à análise dos resultados dos modelos de regressão estimados.

\section{ANÁLISE DE RESULTADOS}

\subsection{ESTATÍSTICA DESCRITIVA DAS VARIÁVEIS}

A Tabela 1 apresenta as estatísticas descritivas das variáveis deste estudo. A respeito dos principais resultados encontrados, nota-se que, em média, o beta foi de 0,86, o que indica que essas empresas apresentam oscilações inferiores ao mercado. $\mathrm{O}$ risco da estrutura interna de capital (WACC) foi de, em média, 35,29, o que sugere alto risco. Sobre o endividamento $(D E)$, em média, as empresas apresentam uma dívida bruta 13,6\% maior que o patrimônio líquido. Ademais, elas se apresentam líquidas, pois a liquidez geral foi de 8,78; o ROA tem média de 1,37, o que retrata que o lucro líquido é superior ao ativo total. Há grande tangibilidade dos ativos, e os valores dos dividendos por ação superam os preços pagos por elas, já que a variável $D y$ teve média de 3,25. E sobre as empresas participantes do ISE, observa-se que cerca de $12,65 \%$ da amostra faz parte desse índice de sustentabilidade da BM\&FBovespa.

Tabela 1 - Estatísticas descritivas das variáveis

(continua)

\begin{tabular}{llllll}
\hline Variável & Obs & Média & Desvio padrão & Min. & Máx. \\
\hline Beta & 434 & 0,8569426 & 0,4326976 & $-0,3423$ & 2,2374 \\
Wacc & 734 & 35,29873 & 341,5106 & $-275,5293$ & 8419,368 \\
De & 880 & 1,136071 & 6,533527 & $-16,37363$ & 188,6 \\
Lnrol & 994 & 7,420523 & 1,93245 & 0 & 13 \\
Liqgeral & 896 & 8,785188 & 29,33283 & 0,0116 & 705,679
\end{tabular}


(conclusão)

\begin{tabular}{llllll}
\hline Variável & Obs & Média & Desvio padrão & Min. & Máx. \\
\hline Roa & 878 & 1,368366 & 26,2796 & $-357,3099$ & 56,9901 \\
Tangib & 879 & 11483,24 & 62544,09 & 0 & 978705 \\
Logvpap & 847 & $-769011,3$ & 1686403 & -9425358 & 6335029 \\
Logvm & 896 & 7,700893 & 1,951318 & 2 & 13 \\
Liquidez & 901 & 0,2366278 & 0,4635393 & 0,0000377 & 4,263734 \\
Dy & 883 & 3,252548 & 13,12597 & 0 & 354 \\
Ise & 1059 & 0,1265345 & 0,3326078 & 0 & 1 \\
\hline F
\end{tabular}

Fonte: os autores.

Na sequência, são apresentados os resultados dos modelos estimados, envolvendo, inicialmente, a análise de regressão Pooled OLS e, posteriormente, a análise de regressão com dados em painel, apresentando os testes de diagnóstico, em especial, os testes de Hausman, testes de heterocedasticidade e de autocorrelação e as principais constatações do estudo. A terminologia para nomear as variáveis está descrita na legenda dos modelos econométricos na seção 3.2 e no Quadro 1. Como comentado na seção 3.1, os modelos estimados foram adaptados de Peixoto (2012) e de Teixeira, Nossa e Funchal (2011).

\subsection{ANÁLISE DA RELAÇÃO ENTRE ISE E WACC - MODELO ADAPTADO DE PEIXOTO (2012)}

A análise da associação entre o ISE e o WACC pode ser observada na Tabela 2. Nota-se a presença dos problemas da heterocedasticidade e da autocorrelação nos dois modelos estimados. Após ser interpretado o resultado do Teste de Hausman (valor p de 0,3464), o modelo foi estimado pelo método de efeitos aleatórios (Random Effects $-R E$ ), com correção robust da matriz de covariância dos coeficientes.

Tabela 2 - Associação entre o ISE e o WACC - Modelo Peixoto (2012)

\begin{tabular}{lll}
\hline Variável & (1) WACC POLS & (2) WACC RE \\
\hline Ise & $-10,4296^{*}$ & $-2,3657$ \\
Beta & $29,5841^{*}$ & 5,5987 \\
Logvpap & $5,6506^{*}$ & 2,8706 \\
Logvm & 1,5659 & $-0,2490$ \\
Liquidez & $27,5854^{* *}$ & 9,6904 \\
Dy & $-0,2610$ & 0,2694 \\
2009 & $-16,4646$ & - \\
2010 & $-22,9234$ & $-12,4820^{*}$ \\
2011 & $-28,5315$ & $-13,1485^{*}$ \\
2012 & & $-15,6000^{* *}$
\end{tabular}


(conclusão)

\begin{tabular}{lll}
\hline Variável & (1) WACC POLS & (2) WACC RE \\
\hline 2013 & $-20,9123$ & $-12,1693^{*}$ \\
Agro e Pesca (Set1) & - & - \\
Alimentos e Beb (Set2) & - & - \\
Comércio (Set3) & $-3,5164$ & $-0,1929$ \\
Construção (Set4) & $-24,9773^{*}$ & $-6,4234$ \\
Eletroeletrônicos (Set5) & $-0,3408$ & $-13,2565$ \\
Energia elétrica (Set6) & $18,0286^{* *}$ & 6,3124 \\
Fundos (Set7) & $200,6763^{*}$ & $197,987^{* * *}$ \\
Minerais Não Met (Set8) & $-32,5015^{*}$ & $-18,9796$ \\
Mineração (Set9) & $-49,1253^{* *}$ & $-20,8446$ \\
Máquinas Industr (Set10) & 3,5945 & 8,9170 \\
Outros (Set11) & $24,9581^{* *}$ & 18,4571 \\
Papel e Celulose (Set12) & 4,4126 & $-3,4412$ \\
Petróleo e Gás (Set13) & $-1,7434$ & 1,1689 \\
Química (Set14) & $-11,9882$ & $-10,2459$ \\
Siderur\&Metalur (Set15) & $-15,6427$ & $-9,3291$ \\
Software e Dados (Set16) & $76,9881^{* * *}$ & 61,1400 \\
Telecomunicações (Set17) & 8,5158 & 2,0289 \\
Têxtil (Set18) & 2,1540 & 7,3341 \\
Transporte Serviç (Set19) & 0,8162 & 0,2186 \\
Veículos e Peças (Set20) & 2,9101 & 3,2978 \\
Constant & $-3,7633$ & 19,1388 \\
\hline Ll & $-3.8 \mathrm{e}+02$ & $-3.8 \mathrm{e}+02$ \\
N & 385 & 385 \\
N_g (número de grupos) & 112 & 112 \\
F & 3,13 & 2,42 \\
P & 0,0000 & 0,0009 \\
\hline Teste de Hausman (valor p) & -- & 0,3464 \\
Teste de Heteroc. de Baum (2001) & 0,0000 & 0,0000 \\
Teste de Autocorr. de Wooldridge (2002) & 0,0000 & 0,0000 \\
\hline & &
\end{tabular}

Fonte: os autores.

Notas: Os asteriscos indicam os níveis de significância: ${ }^{*} \mathrm{p}<0,05$; ${ }^{* *} \mathrm{p}<0,01$; ${ }^{* * *} \mathrm{p}<0,001$. Os modelos estimados são: (1) Pooled OLS ou Mínimos Quadrados Ordinários e (2) Painel com Random Effects (Efeitos Aleatórios). O teste de Hausman apontou a preferência pelo modelo Random Effects (valor p de 0,3464). O teste de heterocedasticidade de Baum (2001) rejeita a hipótese nula de variâncias homocedásticas. O teste de autocorrelação de Wooldridge (2002) rejeita a hipótese nula de ausência de autocorrelação.

Pelo método POLS, foi possível observar relação negativa, ao nível de significância de 5\%, entre o risco da estrutura interna de capital da empresa, representado pela variável WACC, e a variável ISE. Essa evidência corrobora a hipótese deste estudo, e os trabalhos de Vellani, Albuquerque e Chaves (2009), Teixeira, Nossa e Funchal (2011), Nogueira e Gomes (2012) e Lameira et al. (2013). Desse modo, é possível inferir que as empresas pertencentes ao ISE da BM\&FBovespa tendem a reduzir seus riscos. 
Ademais, pelo mesmo método, constatou-se que as variáveis significativas e positivas foram: beta, logvpap, liquidez, setor energia elétrica, setor fundos, setor outros e setor software e dados. Primeiramente, era de se esperar que quanto maior o risco sistemático da empresa (beta), maior o risco da estrutura interna de capital (WACC). O mesmo ocorre em relação às variáveis de controle logvpap e liquidez, que, quando se apresentam maiores, maior é o risco da estrutura interna de capital da firma. Os resultados ainda indicam que estar nos setores como energia elétrica, fundos e software e dados eleva o risco da estrutura interna de capital da empresa em comparação aos demais ramos de atividade.

A respeito das variáveis de controle significativas e negativas do modelo POLS, verificaram-se apenas aquelas relativas a setores, como o de construção, de minerais não metálicos e de mineração. Isso indica que o fato de a firma estar nos setores citados proporciona a ela uma redução nos riscos envolvidos, permitindo concluir que esses setores poderiam proporcionar estabilidade ou, de certa forma, maior previsibilidade na obtenção de resultados e benefícios aos acionistas nos períodos considerados.

Analisando o modelo Random Effects (RE) da Tabela 2, os resultados não apresentaram significância. A priori, nota-se que o ISE não mais possui relação significativa com o risco, diferentemente do observado pelo modelo POLS. Da mesma forma que o ISE, as variáveis de controle, em sua maioria, não se mostraram significativas, com exceção do setor Fundos, positivamente relacionado com a variável WACC. Mas, ainda em termos de variáveis significativas e negativas, é possível apontar as variáveis de ano, entre os quais, 2010, 2011, 2012 e 2013.

\subsection{ANÁLISE DA RELAÇÃO ENTRE ISE E WACC - MODELO TEIXEIRA, NOSSA E FUNCHAL (2011)}

Na Tabela 3 encontram-se os resultados para a associação entre o ISE e o WACC com base no modelo de Teixeira, Nossa e Funchal (2011). Para estimativa do WACC, foram adotados tanto o método POLS quanto o método de regressão com dados em painel, a partir do Painel com Fixed Effects (Efeitos Fixos).

Verificou-se a preferência pelo modelo de Fixed Effects como método para a associação entre as variáveis, o que foi justificado pelo teste de Hausman. O teste de heterocedasticidade de Baum (2001) rejeitou a hipótese nula de variâncias homocedásticas, e o teste de autocorrelação de Wooldridge (2002) rejeitou a hipótese nula de ausência de autocorrelação. Logo, foi usada a rotina robust do Stata 11 para corrigir esses problemas.

Pela análise do modelo POLS, novamente observou-se relação negativa e estatisticamente significativa a $1 \%$, o que corrobora a hipótese deste estudo, indicando que as companhias que apresentam melhores práticas de sustentabilidade, ou seja, que 
estão listadas no ISE, tendem a apresentar menores riscos na percepção interna. No entanto, não houve outras relações significativas observadas.

Tabela 3 - Associação entre o ISE e o WACC - Modelo TNF (2011)

\begin{tabular}{|c|c|c|}
\hline Variável & (1) WACC POLS & (2) WACC FE \\
\hline Ise & $-16,2578 * *$ & 3,5403 \\
\hline LnRec.Líquida & $-6,5622$ & $-72,2871 * * *$ \\
\hline Liquidez Geral & $-0,2655$ & $-0,2059$ \\
\hline ROA & 1,5059 & $5,8743 * * *$ \\
\hline Tangibilidade & $-0,0000$ & $-0,0004$ \\
\hline 2009 & - & - \\
\hline 2010 & $-51,1024$ & $-61,1240 * *$ \\
\hline 2011 & $-34,7879$ & $-44,7087^{*}$ \\
\hline 2012 & $-23,3562$ & $-33,3472 *$ \\
\hline 2013 & $-10,6589$ & $-9,6679$ \\
\hline Agro e Pesca (Set1) & - & - \\
\hline Alimentos e Beb (Set2) & $-10,0023$ & (omitted) \\
\hline Comércio (Set3) & $-11,2326$ & (omitted) \\
\hline Construção (Set4) & 10,2325 & (omitted) \\
\hline Eletroeletrônicos (Set5) & 58,2626 & (omitted) \\
\hline Energia elétrica (Set6) & 12,2628 & (omitted) \\
\hline Fundos (Set7) & $-0,0026$ & (omitted) \\
\hline Minerais Não Met (Set8) & $-0,3025$ & (omitted) \\
\hline Mineração (Set9) & 0,2525 & (omitted) \\
\hline Máquinas Industr (Set10) & $-0,2689$ & (omitted) \\
\hline Outros (Set11) & 10,5959 & (omitted) \\
\hline Papel e Celulose (Set12) & 45,1215 & (omitted) \\
\hline Petróleo e Gás (Set13) & 5,2626 & (omitted) \\
\hline Química (Set14) & $-0,2626$ & (omitted) \\
\hline Siderur\&Metalur (Set15) & 0,3635 & (omitted) \\
\hline Software e Dados (Set16) & $-0,9898$ & (omitted) \\
\hline Telecomunicações (Set17) & $-0,8788$ & (omitted) \\
\hline Têxtil (Set18) & $-0,5252$ & (omitted) \\
\hline Transporte Serviç (Set19) & 0,4548 & (omitted) \\
\hline Veículos e Peças (Set20) & 0,1516 & (omitted) \\
\hline Constant & 83,1527 & 588,9705 \\
\hline $\mathrm{Ll}$ & $-3.8 \mathrm{e}+02$ & $-3.8 \mathrm{e}+02$ \\
\hline $\mathrm{N}$ & 711 & 711 \\
\hline N_g (número de grupos) & 172 & 172 \\
\hline $\mathrm{F}$ & 2,01 & 8,61 \\
\hline $\mathrm{P}$ & 0,0004 & 0,0000 \\
\hline Teste de Hausman (valor p) & - & 0,0000 \\
\hline Teste de Heteroc. de Baum (2001) & 0,0000 & 0,0000 \\
\hline Teste de Autocorr. de Wooldridge (2002) & 0,0000 & 0,0000 \\
\hline
\end{tabular}

Fonte: os autores.

Notas: Os asteriscos indicam os níveis de significância: ${ }^{*} \mathrm{p}<0,05$; ** $\mathrm{p}<0,01$; *** $\mathrm{p}<0,001$. Os modelos estimados são: (1) Pooled OLS ou Mínimos Quadrados Ordinários e (2) Painel com Fixed Effects 
(Efeitos Fixos). O teste de Hausman apontou a preferência pelo modelo Fixed Effects (valor p de 0,0000). O teste de heterocedasticidade de Baum (2001) rejeita a hipótese nula de variâncias homocedásticas. O teste de autocorrelação de Wooldridge (2002) rejeita a hipótese nula de ausência de autocorrelação.

Sobre o modelo Fixed Effects (FE), não se encontrou relação significativa da variável ISE com o WACC, assim como evidenciado pelos demais modelos anteriores de regressão em painel. Seja para o modelo de Painel com Random Effects, seja para o modelo de Painel com Fixed Effects, até então, não foi encontrada nenhuma relação significativa entre o WACC e o ISE.

Mas, ainda no que se refere ao modelo de Efeitos Fixos, observou-se que a rentabilidade sobre o ativo (ROA) está positivamente relacionada ao WACC, o que significa que maior rentabilidade resulta no aumento do risco da estrutura interna da firma. A respeito dos setores, não há informações para esse modelo. Já as variáveis de controle negativas e significativas foram a receita líquida, anos 2010, 2011 e 2012. A receita líquida é uma variável indicativa do tamanho da empresa, permitindo inferir o exposto por Lameira (2012), de que empresas de tamanhos maiores, geralmente, estão associadas a menores riscos.

\subsection{ANÁLISE DA RELAÇÃO ENTRE ISE E DE - MODELO TEIXEIRA, NOSSA E FUNCHAL (2011)}

Além de investigar o impacto que empresas mais sustentáveis produzem sobre o risco, o estudo de Teixeira, Nossa e Funchal (2011) se propôs a analisar o efeito da adesão ao ISE sobre o endividamento. O fato de possuir tal estudo como modelo para as presentes análises torna também interessante investigar essa mesma relação entre o ISE e o DE (relação Debt/Equity ou Endividamento/Capital). Assim, apresenta-se na Tabela 4 a associação entre o ISE e o DE, a partir do método POLS e do Painel com Random Effects (RE - Efeitos Aleatórios).

O teste de efeitos individuais para Fixed Effects e Random Effects revelou que a heterogeneidade não está presente nos dados. Dessa forma, tem-se o Pooled OLS (MQO) como modelo mais adequado a esse caso. Ainda assim, realizou-se o teste de Hausman, que apontou a “preferência” pelo modelo Random Effects. A hipótese nula de variâncias homocedásticas foi rejeitada pelo teste de heterocedasticidade de Baum (2001), e a hipótese nula de ausência de autocorrelação foi rejeitada pelo teste de autocorrelação de Wooldridge (2002).

No modelo POLS, observou-se relação negativa e estatisticamente significativa, ao nível de $0 \%$, entre as variáveis ISE e DE, o que corrobora o trabalho de Teixei- 
ra, Nossa e Funchal (2011), sinalizando que a responsabilidade socioambiental, indicada pelo ISE, pode levar a uma redução do uso de capital de terceiros pelas empresas.

Como variáveis positivas e significativas do método POLS, tem-se: o logaritmo natural da receita líquida (proxy para tamanho), o setor comércio, setor minerais não metálicos, setor química e setor transporte e serviços. Logo, depreende-se que empresas maiores tendem a apresentar maior endividamento. Um maior endividamento pode ser, ainda, resultado de as firmas pertencerem aos setores comércio, minerais não metálicos, química e transporte serviços.

Tabela 4 - Associação entre o ISE e o DE - Modelo TNF (2011)

(continua)

\begin{tabular}{lll}
\hline Variável & $\mathbf{( 1 )} \mathbf{D E}$ POLS & $\mathbf{( 3 )} \boldsymbol{D E} \mathbf{R E}$ \\
\hline Ise & $-0,6499^{* * * *}$ & $-0,6499$ \\
LnRec.Líquida & $0,2215^{* * *}$ & 0,2215 \\
Liquidez Geral & $-0,0064$ & $-0,0064$ \\
ROA & $-0,0305$ & $-0,0305^{* *}$ \\
Tangibilidade & $-5,0107^{* * *}$ & $-5,0107$ \\
2009 & - & - \\
2010 & 0,0353 & 0,0353 \\
2011 & $-0,0428$ & $-0,0428$ \\
2012 & 1,1311 & 1,1311 \\
2013 & 0,3389 & 0,3389 \\
Agro e Pesca (Set1) & - & - \\
Alimentos e Beb (Set2) & $-0,0221$ & $-0,0221$ \\
Comércio (Set3) & $0,8338^{*}$ & 0,8338 \\
Construção (Set4) & 0,4390 & 0,4390 \\
Eletroeletrônicos (Set5) & $-1,0450^{*}$ & $-1,0450$ \\
Energia elétrica (Set6) & 0,6284 & 0,6284 \\
Fundos (Set7) & - & - \\
Minerais Não Met (Set8) & $0,7787^{*}$ & 0,7787 \\
Mineração (Set9) & $-0,9120$ & $-0,9120$ \\
Máquinas Industr (Set10) & 0,4220 & 0,4220 \\
Outros (Set11) & 0,4747 & 0,4747 \\
Papel e Celulose (Set12) & 0,6186 & 0,6186 \\
Petróleo e Gás (Set13) & $-0,9452$ & $-0,9452$ \\
Química (Set14) & $0,9105^{* *}$ & 0,9105 \\
Siderur\&Metalur (Set15) & 0,2517 & 0,2517 \\
Software e Dados (Set16) & 0,2439 & 0,2439 \\
Telecomunicações (Set17) & $-0,1881$ & $-0,1881$ \\
Têxtil (Set18) & 3,9356 & $3,9356^{* *}$ \\
Transporte Serviç (Set19) & $0,7245^{* *}$ & 0,7245 \\
Veículos e Peças (Set20) & 0,2630 & 0,2630 \\
Constant & $-1,0827$ & $-1,0827$ \\
\hline Ll & $-3.8 \mathrm{e}+02$ & $-3.8 \mathrm{e}+02$ \\
N & 841 & 193 \\
N_g (número de grupos) & 193 &
\end{tabular}


(conclusão)

\begin{tabular}{lll}
\hline Variável & (1) DE POLS & (3) $\boldsymbol{D E} \boldsymbol{R E}$ \\
\hline $\mathrm{F}$ & 4,32 & 25,83 \\
$\mathrm{P}$ & 0,0000 & 0,0009 \\
\hline Teste de Hausman (valor p) & - & 0,4206 \\
Teste de Heteroc. De Baum (2001) & 0,0000 & 0,0000 \\
Teste de Autocorr. De Wooldridge (2002) & 0,0000 & 0,0000 \\
\hline Fonte: os autores. & &
\end{tabular}

Fonte: os autores.

Notas: Os asteriscos indicam os níveis de significância: * $\mathrm{p}<0,05$; ${ }^{* *} \mathrm{p}<0,01$; *** $\mathrm{p}<0,001$. Os modelos estimados são: (1) Pooled OLS ou Mínimos Quadrados Ordinários e (2) Painel com Random Effects (Efeitos Aleatórios). O teste de efeitos individuais para Fixed Effects e Random Effects revelou que a heterogeneidade não está presente nos dados. Logo, o modelo mais ajustado nesse caso é o Pooled OLS (MQO). Mesmo assim, procedeu-se ao teste de Hausman, que revelou a "preferência” pelo modelo Random Effects (valor p de 0,4206). O teste de heterocedasticidade de Baum (2001) rejeita a hipótese nula de variâncias homocedásticas. O teste de autocorrelação de Wooldridge (2002) rejeita a hipótese nula de ausência de autocorrelação.

Quanto às variáveis negativas e significativas, tem-se a tangibilidade e o setor eletroeletrônicos. A respeito da tangibilidade, a provável conclusão é de que empresas com maior volume de ativos tangíveis apresentem menor endividamento (TEIXEIRA; NOSSA; FUNCHAL, 2011). Infere-se, também, que pertencer ao setor de eletroeletrônicos significa ter uma estrutura de capital menos alavancada.

Quando se passa para a análise do método de Efeitos Aleatórios (RE) sobre o endividamento $(D E)$, percebem-se poucas variáveis significativas. Também não foi possível presumir a relação entre o ISE e o endividamento.

Sendo o setor têxtil a única variável significante e positiva encontrada, fica o indicativo desse setor como mais propenso ao endividamento no período estudado.

E, por fim, uma variável significativa negativamente relacionada foi o ROA, ou seja, a rentabilidade do ativo. Tal resultado corrobora a ideia de Teixeira, Nossa e Funchal (2011), ao afirmarem que a rentabilidade mantém uma relação inversa com o endividamento.

\section{CONCLUSÃO}

A tendência de valorizar empresas que possuem e colocam em prática princípios de sustentabilidade em sua gestão engloba, por exemplo, a consideração de que elas tenham maior conhecimento dos riscos e oportunidades do negócio. Isso aumenta a probabilidade de que realizem uma gestão de riscos mais eficiente, permitindo que sejam vistas pelos investidores como uma fonte mais segura para os seus investimentos de longo prazo. Esse tipo de segurança passa a ser ainda mais importante quando 
os investidores percebem a necessidade de reavaliarem seus critérios de investimento, focando a gestão dos riscos do negócio.

Pensando nessa tendência e nos impactos gerados pela sustentabilidade empresarial, a proposta com este trabalho foi verificar se existe relação entre uma empresa aderir ao Índice de Sustentabilidade Empresarial e o seu custo de capital/endividamento.

Os resultados deste estudo tornam possível entender, estatisticamente, que há indícios de que exista relação entre a adesão ao ISE e o risco interno da estrutura de capital, bem como o nível de endividamento, o que corrobora os trabalhos de Vellani, Albuquerque e Chaves (2009), Teixeira, Nossa e Funchal (2011), Nogueira e Gomes (2012) e Lameira et al. (2013). Esses indícios partem das relações significativas e negativas presentes em todos os modelos econométricos que analisam a relação entre ISE e WACC e entre ISE e DE, com base no método dos mínimos quadrados ordinários (POLS - Pooled OLS). Esses resultados sugerem que o ISE pode ser uma ferramenta útil e positiva para as empresas socioambientalmente responsáveis melhorarem o relacionamento com stakeholders.

Entretanto, para o método de análise de regressão com dados em painel, constatou-se que não é possível concluir que empresas aderentes ao Índice de Sustentabilidade Empresarial (ISE) apresentem condições diferenciadas no que se refere ao custo de capital/endividamento em relação àquelas que não aderem ao índice. Esse resultado baseou-se na ausência de relação significativa entre as variáveis WACC/ endividamento e o ISE.

Ainda assim, de forma geral, a análise quantitativa dos dados por meio das abordagens aplicadas permitiu a identificação de relação entre diferentes variáveis, sejam de controle, dummies de setor, sejam de ano. Pelos resultados observados, foi possível notar que as empresas pertencentes aos setores de energia elétrica, fundos e software e dados tendem a ter uma elevação no risco da estrutura interna de capital, enquanto as que fazem parte dos setores de construção, de minerais não metálicos e de mineração tendem a ter seus riscos reduzidos. Infere-se, ainda, que as empresas do setor de eletrônicos tendem a apresentar uma estrutura de capital menos alavancada. A visualização das relações significativas entre estas com variáveis de risco interno e endividamento culminou em observações interessantes, possibilitando compreender os prováveis comportamentos e impactos no mercado e, por consequência, nas empresas estudadas.

Nesta pesquisa, obtiveram-se resultados que se limitam à amostra analisada e ao período adotado, de 2009 a 2013. Além disso, os resultados também se limitam aos modelos propostos, visto que outros fatores e variáveis poderiam ser incluídos como parte da análise. Ressalta-se que esta pesquisa apresentou contribuições teóri- 
cas e práticas, por envolver um tema que tem sido especialmente analisado nas duas últimas décadas. A contribuição teórico-empírica compreendeu o entendimento da relação estabelecida entre a adesão ao ISE e o custo de capital e endividamento das organizações. A carência de estudos que relacionam essas temáticas mostra a relevância deste estudo para a área de Finanças. A contribuição prática, por sua vez, está relacionada à investigação se as empresas mais sustentáveis de fato garantem maior valor aos acionistas em longo prazo.

Para próximos trabalhos, sugere-se a adoção de novos modelos econométricos, fazendo uma distribuição de variáveis diferenciada em relação aos modelos utilizados neste estudo. Pode-se, por exemplo, utilizar outras variáveis indicativas de risco, como beta, volatilidade e custo de capital de terceiros, pois em finanças também são usadas como representativas do risco das empresas. Dessa forma, novas perspectivas e observações podem ser feitas sobre o tema.

\section{REFERÊNCIAS}

ANDERSON, D. Sustainability risk management. CPCU eJournal, v. 59, i. 5, 2006.

ANDRADE, L. P. de; MOREIRA, B. C. de M.; PEDROSA, G. H. Determinantes da performance de sustentabilidade empresarial: uma nova análise sobre as empresas brasileiras de capital aberto. In: ENCONTRO DA ASSOCIAÇÃO NACIONAL DE PÓS-GRADUAÇÃO E PESQUISA EM ADMINISTRAÇÃO, 36., 2012, Rio de Janeiro. Anais... Rio de Janeiro: ANPAD, 2012.

ARBACHE, A. P. Coletânea sobre cenários e projetos sustentáveis nas empresas brasileiras é lançada no mercado editorial. 2012. Disponível em: <http://www.arbache.com/blog/2012/11/colet\%C3\%A2nea-sobre-cen\%C3\%A1rios-e projetos-sustent\%C3\%A1veis-nas-empresas-brasileiras-\%C3\%A9-lan\%C3\%A7ada-no-mercado-editorial.html>. Acesso em: 20 fev. 2014.

ARBACHE, A. P. Resumo: o desenvolvimento sustentável em 2012 no Brasil. 2013. Disponível em: <http://www.arbache.com/blog/2013/01/resumo-o-desenvolvimento-sustent\%C3\%A1vel-em-2012-no-brasil.html> . Acesso em: 20 fev. 2014.

ARTIACH, T. et al. The determinants of corporate sustainability performance. Accounting Finance, v. 1, i. 50, p. 31-51, 2010.

ASSAF NETO, A. Finanças corporativas e valor. 4. ed. São Paulo: Atlas, 2009.

ASSAF NETO, A. Mercado Financeiro. 7. ed. São Paulo: Atlas, 2006. 
BISCO, E. Sustentabilidade empresarial: um estudo comparativo sobre o desempenho e valor financeiro de empresas listadas no mercado acionário brasileiro. 2009. 110 p. Dissertação (Mestrado em Administração)-Universidade Metodista de São Paulo, São Paulo, 2007.

BM\&FBOVESPA. ISE - Sustentabilidade Empresarial. São Paulo, 2014a. Disponível em: <http://www.bmfbovespa.com.br/Pdf/Indices/ISE.pdf>. Acesso em: 03 mar. 2014.

BM\&FBOVESPA. Metodologia do Índice de Sustentabilidade Empresarial. São Paulo, 2014b. Disponível em: <http://www.bmfbovespa.com.br/Indices/download/ ISE-Metodologia-pt-br.pdf>. Acesso em: 12 mar. 2014.

CAVALCANTI, J. M. M.; BOENTE, D. R. A relação de risco e retorno nas empresas integrantes do índice de sustentabilidade empresarial no período de 2008 a 2010. Revista Ambiente Contábil - UFRN, v. 4, n. 1, p. 51-71, 2012.

CLARO, P. B. de O.; CLARO, D. P.; AMÂNCIO, R. Entendendo o conceito de sustentabilidade nas organizações. Revista de Administração, v. 43, n. 4, p. 289-300, 2008.

CLARO, P. B. de O.; CLARO, D. P.; ARAKI, Y. T. Como o investimento socioambiental afeta desempenho das empresas em épocas de crise financeira? In: ENCONTRO DA ASSOCIAÇÃO NACIONAL DE PÓS-GRADUAÇÃO E PESQUISA EM ADMINISTRAÇÃO, 37., 2013, Rio de Janeiro. Anais... Rio de Janeiro: ANPAD, 2013.

DAMODARAN, A. Avaliação de investimentos: ferramentas e técnicas para a determinação do valor de qualquer ativo. 4. ed. Rio de Janeiro: Qualitymark, 2002.

DIAS, R.; ZAVAGLIA, T.; CASSAR, M. Introdução à administração: da competitividade à sustentabilidade. Campinas: Alínea, 2003.

ELKINGTON, J. Cannibals with Forks. Gabriola Island: New Society Publishers, 1998.

HARRIS, J. et al. A survey of sustainable development: social and economic dimensions. Washington: Island, 2001.

HARRIS, M.; RAVIV, A. The theory of capital structure. Journal of Finance, v. 46, p. 297-355, 1991. 
KRAEMER, M. E. P. Responsabilidade social: um olhar para a sustentabilidade. Gestión Ambiental y Sostenibilidad, 2005. Disponível em: $<$ http://www.gestiopolis.com/Canales4/ger/responsabilidade.htm>. Acesso em: 03 jan. 2014.

LAMEIRA, V. de J. As relações entre governança e risco nas companhias abertas brasileiras. Revista Brasileira de Gestão de Negócios, v. 14, n. 42, p. 7-25, 2012.

LAMEIRA, V. de J. et al. Sustentabilidade, valor, desempenho e risco no mercado de capitais brasileiro. Revista Brasileira de Gestão de Negócios, v. 15, n. 46, p. 76-90, 2013.

LAMEIRA, V. J. Governança corporativa, risco e desempenho das companhias abertas brasileiras - uma análise do relacionamento entre as práticas de governança corporativa, o risco e o desempenho das companhias abertas brasileiras. 2007. 197 p. Tese (Doutorado em Administração)-Pontifícia Universidade Católica do Rio de Janeiro, Rio de Janeiro, 2007.

MARCONDES, A. W.; BACARJI, C. D. ISE - Sustentabilidade no mercado de capitais. 1. ed. São Paulo: Report, 2010. Disponível em: <http://www.bmfbovespa. com.br/pt-br/a-bmfbovespa/download/Livro_ISE.pdf>. Acesso em: 29 jan. 2014.

MATARAZZO, D. C. Análise financeira de balanços: abordagem básica e gerencial. 6. ed. São Paulo: Atlas, 2007.

MYERS, S. C. The capital structure puzzle. The Journal of Finance, v. 39, i. 3 p. 575-592, 1984.

NOGUEIRA, C. M. da S.; GOMES, A. C. C. Desempenho do Índice de Sustentabilidade Empresarial (ISE) sob a perspectiva do Retorno Ajustado ao Risco: sustentabilidade gera retorno? Revista Espaço Acadêmico, n. 131, 2012.

OLIVEIRA, A. C. S. Sustentabilidade corporativa: uma análise dos efeitos da adoção de práticas sustentáveis sobre o desempenho de mercado e operacional. 2013. 50 p. Dissertação (Graduação em Administração)-Universidade Federal de Uberlândia, Uberlândia, 2013.

PEIXOTO, F. M. Governança corporativa, desempenho, valor e risco: estudo das mudanças em momentos de crise. 2012. Tese (Doutorado em Administração)-Universidade Federal de Minas Gerais, Belo Horizonte, 2012. 
RUF, B. M. et al. An empirical investigation of the relationship between change incorporate social performance and financial performance: a stakeholder theory perspective. Journal of Business Ethics, v. 32, p. 143-156, 2001.

SCHALTEGGER, S.; BURRITT, R. Contemporary Environmental Accounting Issues, Concepts and Practice. Sheffield: Greenleaf, 2000.

SILVEIRA, A. D. M. Governança corporativa e estrutura de propriedade: determinantes e relação com o desempenho das empresas no Brasil. 2004. 250 p. Tese (Doutorado em Administração)-Universidade de São Paulo, São Paulo, 2004.

SKAIFE, H. A.; COLLINS, D. W.; LAFOND, R. Corporate governance and the cost of equity capital. WorkingPaper, 2004. Disponível em: <http://ssrn.com/abstract=639681>. Acesso em: 05 maio 2010.

TEIXEIRA, E. A.; NOSSA, V.; FUNCHAL, B. O índice de sustentabilidade empresarial (ISE) e os impactos no endividamento e na percepção de risco. Revista Contabilidade \& Finanças, v. 22, n. 55, p. 29-44, 2011.

VELLANI, C. L.; ALBUQUERQUE, A. A de; CHAVES, E. de P. e S. Uma tentativa de mensuração da relação entre valor de mercado e sustentabilidade empresarial nas ações listadas no ISE da Bovespa. In: ENCONTRO DA ASSOCIAÇÃO NACIONAL DE PÓS-GRADUAÇÃO E PESQUISA EM ADMINISTRAÇÃO, 38., 2009, São Paulo. Anais... São Paulo: ANPAD, 2009.

VITAL, J. T. et al. Influência da participação no Índice de Sustentabilidade Empresarial (ISE) no desempenho financeiro das empresas. Revista de Ciências da Administração, v. 11, n. 24, p. 11-40, 2009.

WAJNBERG, D.; LEMME, C. F. Exame da divulgação do relacionamento entre iniciativas socioambientais e desempenho financeiro corporativo nos bancos brasileiros. Revista de Gestão Social e Ambiental, n. 3, p. 53-69, 2009.

Nota explicativa:

${ }^{1}$ Conforme Damodaran (2002, p. 299), para o cálculo do Custo Médio Ponderado de Capital (WACC), foi utilizada a fórmula:

$\mathrm{WACC}=\left\{\frac{\left[\mathrm{EBIT}^{*}(1-\mathrm{T})+\mathrm{D}-\mathrm{I}\right]}{(\mathrm{EQUITY}+\mathrm{DEBT})} *[1+(1-\right.$ Payout $) *$ ROA $\left.]\right\}+[(1-$ Payout $) *$ ROA $]$ 
Em que: EBIT: lucros antes de juros e impostos; T: alíquota de imposto de renda (fixa); D: valor da depreciação incorrida no período; I: valor do investimento feito pela empresa (Capital Employed ou Capital Aplicado - o mesmo que capital investido pela empresa no período); EQUITY: Valor de mercado das ações da empresa; DEBT: Valor contábil da dívida da empresa = Passivo Circulante + Exigível em Longo Prazo + Estoques - Ativo Circulante; Payout: percentual do lucro destinado ao pagamento de dividendos; ROA: razão entre o lucro operacional e os ativos totais da empresa; WACC: abreviatura de Weighted Average Costof Capital, ou seja, custo médio ponderado de capital da empresa.

Como citar este artigo:

\section{ABNT}

PEIXOTO, Fernanda Maciel; PAINS, Marielle Barcelos; ARAÚJO, Aracy Alves de; GUIMARÃES, Thayse Machado. custo de capital, endividamento e sustentabilidade empresarial: um estudo no mercado de capitais brasileiro no período de 2009 a 2013. RACE: Revista de Administração, Contabilidade e Economia, Joaçaba: Ed. Unoesc, v. 15, n. 1, p. 39-66, jan./abr. 2016. Disponível em: <http://editora.unoesc.edu.br/ index.php/race> . Acesso em: dia/mês/ano.

\section{APA}

Peixoto, F. M., Pains, M. B.; Araújo, A. A. de, \& Guimarães, T. M. (2016). Custo de capital, endividamento e sustentabilidade empresarial: um estudo no mercado de capitais brasileiro no período de 2009 a 2013. RACE: Revista de Administração, Contabilidade e Economia, 15(1), 39-66. Recuperado em dia/mês/ano, de http://editora.unoesc.edu.br/index.php/race 